\title{
Study on the Problems and Countermeasures of Interior Auditing of Enterprise Groups in China
}

\author{
Zhaoliang Wang \\ Institute of Petroleum Economics \& Management \\ Northeast Petroleum University, Daqing 163318, China \\ E-mail: dqwangzhaoliang@163.com
}

Received: December 15, $2010 \quad$ Accepted: January 10, 2011 doi:10.5539/ibr.v4n2p201

\begin{abstract}
In recent years, some problems existing in the interior auditing of Chinese enterprise groups have directly or indirectly influenced the enhancement of the management and economic benefit of enterprise group. In this article, based on detailed analysis of these problems, following countermeasures are put forward, including perfecting the management mode of interior auditing, perfecting the program of interior auditing, performing the interior auditing by computer, and enhancing the auditors' quality of interior auditing.
\end{abstract}

Keywords: Enterprise group, Interior auditing, Mode, Auditors' quality

\section{Introduction}

Enterprise group is the business entity association with certain scale, which is composed by the parent company, the subsidiary companies, the joint stock companies, and other member enterprises or institutions taking the parent company and subsidiary companies linked by capitals as the main body, and taking the group constitution as the common behavior standards.

The member enterprises in the enterprise group are not in a mess. To harmonize the management among member enterprises to form the join forces in the group, effectively distribute resources of the group, ensure the realization of the group target, manage the group better for the highest management layer, enhance the efficiency of the group, the economical efficiency and the legality of the economic management of all member enterprises should be evaluated and supervised, so the interior auditing of the enterprise group occur, and it supervises and evaluates the financial income and expenses, and the economic activities of the group company, the subsidiary company, the holding companies, and the joint stock companies according to relative laws and regulations by the professional auditing institutions and auditors in the group, to perfect the management of the whole group and enhance the economic benefit.

\section{Problems existing in the interior auditing of Chinese enterprise groups}

In 1983, large and medium-sized state-owned enterprise of China successively established their interior auditing institutions and implemented the interior auditing supervision. After 20 years' development, the interior auditing of China has been developed very well, and at present, there are about thirty thousands interior auditors in China, and the structure of auditors begin to become reasonable, and in many industries such as petroleum, electric power, and aviation, the chief auditor system has been implemented, and the interior auditing institutions have exerted active functions to strengthen the management and enhance the economic benefits. But at present, the interior auditing of enterprise group in China is still in the initial stage, and still has some problems as follows.

\subsection{The interior auditing institutions of enterprise groups have weak independence and bad objectivity}

Most enterprise groups adopt the general management leading mode, and the interior auditing is leaded by the general manager directly, which works in the general manager's scope of authority and is parallel with other departments. First, the interior auditing institution is leaded by the general manager, integrating the implementation and supervision function, which would not effectively supervise general manager's economic responsibility and management behaviors. Second, the interior auditing institution is parallel with other functional departments, so it usually could not supervise and evaluate those financial department and other management departments on its layer, and it could only audit underling departments.

\subsection{The functions of the interior auditing of enterprise group have not be exerted sufficiently}

As viewed from the development history of interior auditing, there are three layers. The first one is the financial 
auditing, and the second one is the operational auditing, and the third one is the management auditing. The interior auditing of Chinese enterprise group started from financial auditing, i.e. mainly checking the legality and rationality of financial income and expenses and the authenticity of accounting information, and the auditing objects mainly include accounting reports, account book, certificates, and relative materials. In the practice, the interior auditing in most companies is to check errors and compensate losses, and the emphasis is the financial auditing, and it could not systematical and authoritatively evaluate the interior control system of the enterprise, so it could not discover and objectively evaluate the potential risk of the enterprises, and could not put forward essential and predictive management advices to the management administration. The interior auditing in the present stage could not fully exert the important function of the interior auditing in the enterprise group, because the real task of the interior auditing is to provide necessary decision-making information for enterprise managers and promote managers to enhance the management level and economic benefits by the prior prediction, stage supervision, and past auditing.

\subsection{The interior auditing measures of enterprise groups are lagged}

At present, most large-scale enterprise groups have realized the networking of information system, and the computer network system in the group could centralize all fund flows and budget enforcements, and the parent company could transfer the financial state of subsidiary companies at any time, and supervise the management of subsidiary companies real time. However, many works of the interior auditing institutions of many Chinese enterprise groups have still been in the testing stage of manual operation, which could not adapt the requirements of the development obviously, and could not supervise the management and decision-makings for the enterprises.

\subsection{Auditors' quality of interior auditing of enterprise groups is lower}

With the transformation of the interior auditing of enterprise group from financial auditing to operational auditing and management auditing, the quality of interior auditors should be higher and higher. But most interior auditors of Chinese enterprise groups were from financial employees, and many of them have not been trained systematically and professionally, lacking in the knowledge and experience of management. According to relative statistics, in 12 millions of accounting employees, only about $20 \%$ of them have been educated above middle level.

\section{Countermeasures to perfect the interior auditing of Chinese enterprise group}

At present, above problems in the interior auditing of Chinese enterprise groups have seriously influenced the interior control and risk-resistance for enterprise groups, so following countermeasures are suggested.

\subsection{Perfecting the management mode of interior auditing and strengthening the independence and subjectivity of the interior auditing institutions of enterprise groups}

The establishment and management of the interior auditing institution in modern enterprise groups should flexibly select and use the interior auditing management mode according the institution of the enterprise group. First, for the auditing committee of enterprise group under the directorate of the group company, the committee members should be assumed by non-executive directors, and independent directors should occupy most posts, and some enterprises could invite the principals of some operation departments or external experts, and this committee should be authorized by the board of directors and be the permanent institution. The auditing committee is subject to the board of directors, and it directly reports to the board of directors, without the limitations from the management layer and the operation departments, and it should perform its responsibilities independently. Second, the auditing agency of the subsidiary company has not the legal personality, but the core subsidiary company in the group should have professional auditors or establish the auditing agency, which could supervise the daily auditing to the subsidiary company, or else, the subsidiary company should accept the direct supervision of the auditing committee of the group company. Third, for the independent auditing institution of the subsidiary company, the subsidiary company with the legal personality should independently establish the interior auditing institution independently according to the management scale. The interior auditing institution should be leaded under the board of directors of the subsidiary company, and the auditing institution of the subsidiary company should be responsible for the group auditing committee, and the subsidiary company could also have not the independent auditing institution, and the auditing committee of the group company should establish the auditing agency in the subsidiary, which should be agreed by the board of directors of the subsidiary company. The auditing committee leads the interior auditing, which could strengthen the independence and authority of the interior auditing, and fully exert the supervision function of the interior auditing.

\subsection{Perfecting the interior auditing programs and fully exerting the interior auditing function}

To transform the work procedure and establish the whole-course supervision interior auditing work mode including pre-event prevention, mid-event supervision, and after-event auditing, and run through the whole course of the management, could realize the anticipated benefit of the enterprise group. The present interior auditing of China 
places extra emphasis on the after-event auditing, and pay attention to the pre-event prevention and the mid-event supervision not enough, which could not eliminate risks and losses in the initial stage, and can not effectively prevent the risk, reduce the losses, and enhance the management efficiency. Therefore, the focus of the auditing work should be transferred from the traditional after-event auditing to the whole-course supervision interior auditing work mode including pre-event prevention, mid-event supervision. In the practice, not only the important management decision-makings, the key investment projects, and the purchase and sale business occupying large numerous of capitals of the enterprise group should be audited before the event, but also the materials and budgets about the feasibility and the authenticity, the rationality, and the validity of the economic contract should be supervised and evaluated, to feed back the information and prevent the faults. At the same time, to implement effective supervision and check in the implementation of project or work could discover and correct faults in time, and eliminate risk, hidden troubles, and losses in the initial stage.

\subsection{Perfecting the measures and methods of interior auditing and using computer to perform interior auditing}

In many large enterprise groups, the networking of the computer information system has been realized basically, and both the auditing environment and the auditing objects are more complex, and if auditors still use the manual operation mode, the auditing target is hard to achieve. Therefore, the enterprise group should strengthen the technology investment in the interior auditing of enterprise to break the interior auditing work of enterprise away from the manual operation, and enter into the development stage of information and standardization early, and adapt the interior auditing work of enterprise under variable situations by modern and scientific measures. Auditors' operation measure should transform from manual operation to computer operation, i.e. auditors should grasp the computer knowledge and relative application technologies, develop new auditing procedures, establish more careful auditing plan, and use the computer as a kind of powerful toll to enhance the auditing quality and efficiency.

\subsection{Enhancing auditors' quality of interior auditing and optimizing the group structure}

The quality of interior auditing is largely determined by interior auditors' quality. Auditors' quality should be further enhanced, and their knowledge about finance, statistics, economic activity analysis, financial tax, marketing, writing, and computer should be trained periodically, and their subsequent education and moral education should be also strengthened to cultivate their sensitive insight and judgment. At the same time, the interior auditing group of the group should not only limit in financial employees, but professional employees with the knowledge of computer, engineering, technology, law, and management, and more wide management technologies should be grasped, to make the knowledge structure of the interior auditing be more reasonable. When large-scale group company establishes the interior auditing institution, the interior auditing group should come from not only professional interior auditors, but also other professionals such as legal adviser, engineering technician, economic engineer, statistician, computer engineer to form the join force.

\section{References}

Guo, Haiyan. (2004). Development Tendency and Countermeasures of Interior Auditing of China. Journal of Heibei University of Economics and Trade. No.6.

Li, Hanghui. (2005). Perfecting the Interior Auditing of Enterprise Group. Development Research. No.5.

Song, Weimin. (2005). Problems and Countermeasures of Interior Auditing of China at the Present Stage. Friends of Accounting. No.4.

Zhang, Qiaoliang, Zhang, Lei \& Xu, Yuejun. (2005). Study on the Value Increment Function of Interior Auditing. Friends of Accounting. No.4. 